\title{
Crown Dilaceration in Permanent Teeth after Trauma to the Primary Predecessors: Report of Three Cases
}

\author{
Talitha de Siqueira MELLARA \\ Paulo NELSON-FILHO \\ Alexandra Mussolino de QUEIROZ \\ Milton SANTAMARIA JÚNIOR \\ Raquel Assed Bezerra da SILVA \\ Lea Assed Bezerra da SILVA \\ Department of Pediatric Clinic, Ribeirão Preto Dental School, \\ USP - University of São Paulo, Ribeirão Preto, SP, Brazil
}

\begin{abstract}
Crown dilaceration of permanent teeth occurs due to the non-axial displacement of the already formed hard tissue portion of the developing crown at an angle to their longitudinal axis due to trauma to the primary predecessors. This is a rare condition, representing only $3 \%$ of the total of injuries to developing teeth and usually occurs in permanent maxillary incisors because of the close proximity of their tooth germs to the primary incisors, which are more susceptible to trauma. This alteration frequently results from the intrusion of a primary tooth when the child is around 2 years of age, at which time half of the crown of the permanent successor is already formed. Teeth with dilacerated crowns may either erupt with buccal or lingual displacement or remain impacted. The treatment may involve endodontic, orthodontic, restorative and prosthetic procedures. This paper reports the restorative treatment proposed to reestablish the esthetics and function of the affected teeth in three cases of crown dilaceration in permanent maxillary incisors after trauma to their primary predecessors.
\end{abstract}

Key Words: trauma, crown dilaceration, primary dentition.

\section{INTRODUCTION}

Traumatic injuries to primary teeth can result in a wide range of disturbances to their permanent successors. Type and severity of the disturbance depends on the stage of tooth development (age at the time of injury), relationship of the permanent tooth to the roots of primary tooth, and direction and degree of force. Sequelae to the permanent dentition after trauma to the primary predecessors are usually related to intrusive injuries $(1,2,3)$, which often result in an anomalous development of the permanent tooth germ with an incidence of 12 to $74 \%(1,4)$. Trauma to the primary dentition may affect the coronal or root region or the whole permanent tooth germ (5). Sequelae are frequently found in the coronal region in the form of structural alterations, e.g. white, yellow or brown discoloration, enamel hypoplasia and crown dilaceration $(5,6)$.

Crown dilaceration of permanent teeth occurs due to the non-axial displacement of the already formed hard tissue portion of the developing crown at an angle to their longitudinal axis due to trauma to the primary predecessors. This is a rare condition, representing only $3 \%$ of the total of injuries to developing teeth $(7,8)$ and usually occurs in permanent maxillary incisors because of the close proximity of their tooth germs to the primary incisors, which are more susceptible to trauma $(6,9,10)$. Crown dilacerations with palatal angulation of the crown occur most commonly in maxillary incisors, whereas labial angulation is more common in mandibular incisors $(6,10)$. The treatment of dilacerated teeth may involve endodontic, orthodontic, restorative and prosthetic procedures, and others $(3,11)$.

This paper reports 3 cases in which composite 
resin restorations were the treatment of choice to recover the esthetics and function of permanent maxillary anterior teeth that developed crown dilaceration after trauma to their primary predecessors.

\section{CASE REPORT}

This case presentation was approved by the Ethics Committee of Ribeirão Preto Dental School, University of São Paulo, Brazil (Protocol \#2009.1.643.58.0).

\section{Case 1}

An 11-year-old Caucasian male child was brought to the Pediatric Dentistry Clinic of the Ribeirão Preto Dental School, University of São Paulo, Brazil, with esthetic complaints on the permanent maxillary right and left central incisors.

The child was healthy and had no history of systemic diseases. According to the mother's report, the patient had suffered trauma to the anterior maxilla at 2 and a half years of age due to a bicycle fall and, at that time, clinical and radiographic examination at an emergency dental service revealed intrusion of the primary maxillary incisors, which were extracted at that moment. However, the dentist did not instruct the mother about the need of follow up neither informed about the possible occurrence of sequelae to the successor permanent dentition. The mother reported that the permanent successors erupted with alterations of color and shape, which had always been a reason of dissatisfaction to the patient.

As part of the treatment plan, a periapical radiograph confirmed the presence of crown dilaceration on the maxillary right and left central incisors (Fig.1A). The intraoral clinical examination revealed alterations in the incisal and middle thirds of these teeth, which presented crown displacement to the palatal side. Carious lesions were observed on both buccal and palatal sides of the tooth crown along the junction between the dilacerated and non-dilacerated portions, probably due to the greater accumulation of biofilm in this region.
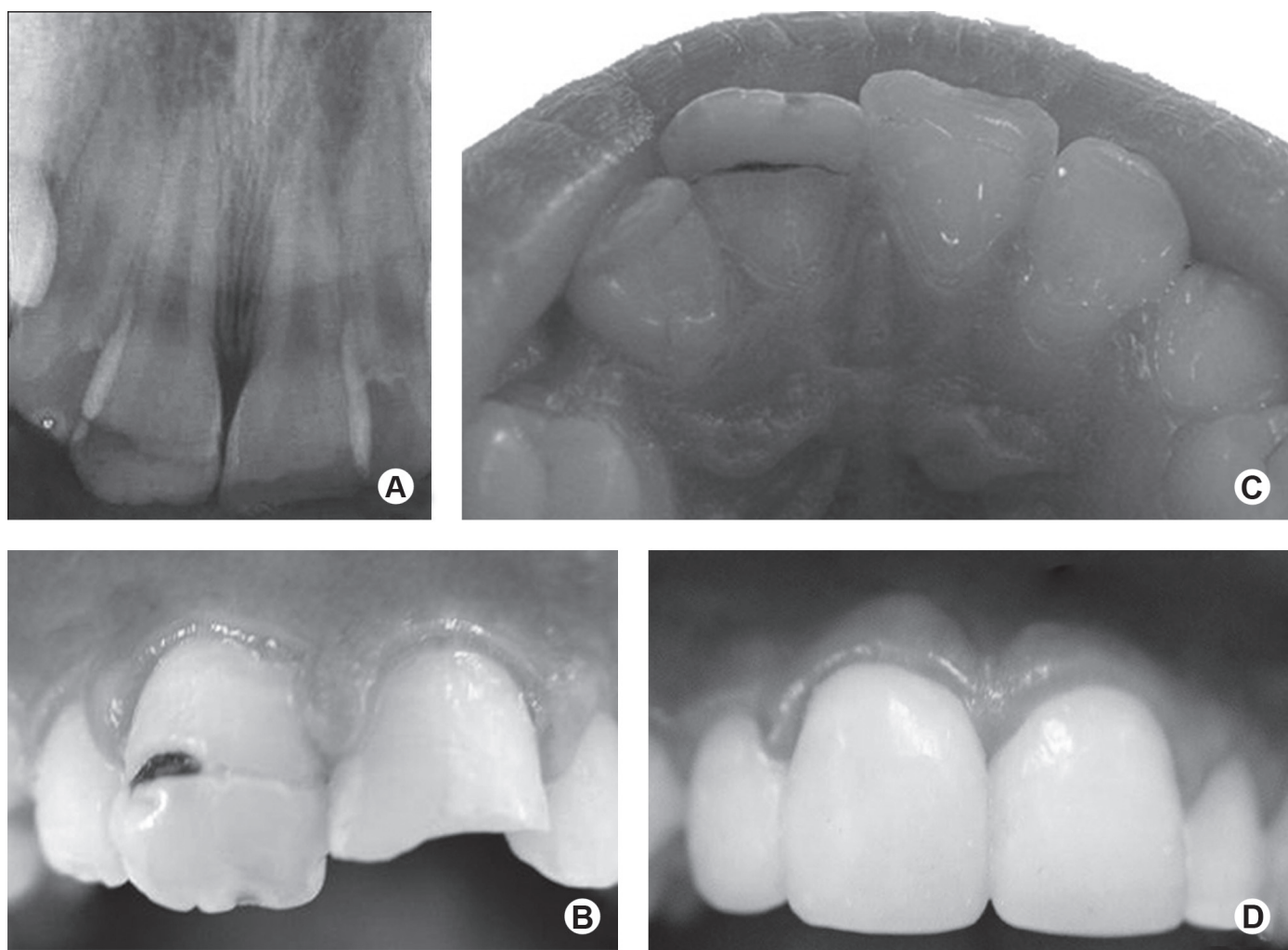

Figure 1. Case 1. A: Periapical radiograph of the permanent maxillary central incisors, showing the presence of crown dilaceration. $\mathrm{B}$ : Clinical aspect of crown dilaceration in the maxillary right central incisor. C: Incisal and palatal views of the permanent maxillary central incisors. D: Clinical aspect after composite resin restoration. 
Hypoplastic areas were observed on the incisal third of both maxillary central incisors. The maxillary left central incisor presented an enamel/dentin crown fracture caused by another trauma suffered after eruption of this tooth (Fig. 1B and 1C).

After removal of the carious tissue, the dilacerated areas on both maxillary central incisors and the crown fracture in the maxillary left central incisor were restored using a single-bottle etch-and-rinse adhesive system (Single Bond; 3M ESPE, St. Paul MN, USA) and a hybrid composite resin (Filtek Z250 Universal Restorative; 3M ESPE; shade A2). An incremental restorative technique was used and the materials were polymerized with a halogen light source (Ultralux; Dabi Atlante, Ribeirão Preto, SP, Brazil) (Fig. 1D).

\section{Case 2}

A 9-year-old Caucasian female child was brought to the same, complaining of the esthetics of the maxillary left central incisor (Fig. 2a). The child was healthy and had no history of systemic diseases. The mother reported a previous trauma to the anterior maxilla at 2 years of age caused by a fall. At the time, the primary maxillary left central incisor suffered an intrusion and was followed clinically and radiographically until its spontaneous eruption. However, after 3 months of follow up, there was no longer response to the pulp vitality tests and a radiographically visible periapical lesion had developed. Thus, the primary maxillary left central incisor was treated endodontically and restored with composite resin.

The patient returned after 7 years complaining of esthetic alterations on the permanent maxillary left central incisor. The radiographic (Fig. 2A) and clinical (Fig. 2B) examinations revealed crown dilaceration affecting the incisal and middle thirds of the crown on both buccal and palatal sides, with hypoplastic areas exhibiting exposure of yellowish dentinal tissue. The incisal portion of the maxillary left central incisor was palatally displaced (Fig. 2B and 2C).

After removal of the carious tissue and indirect
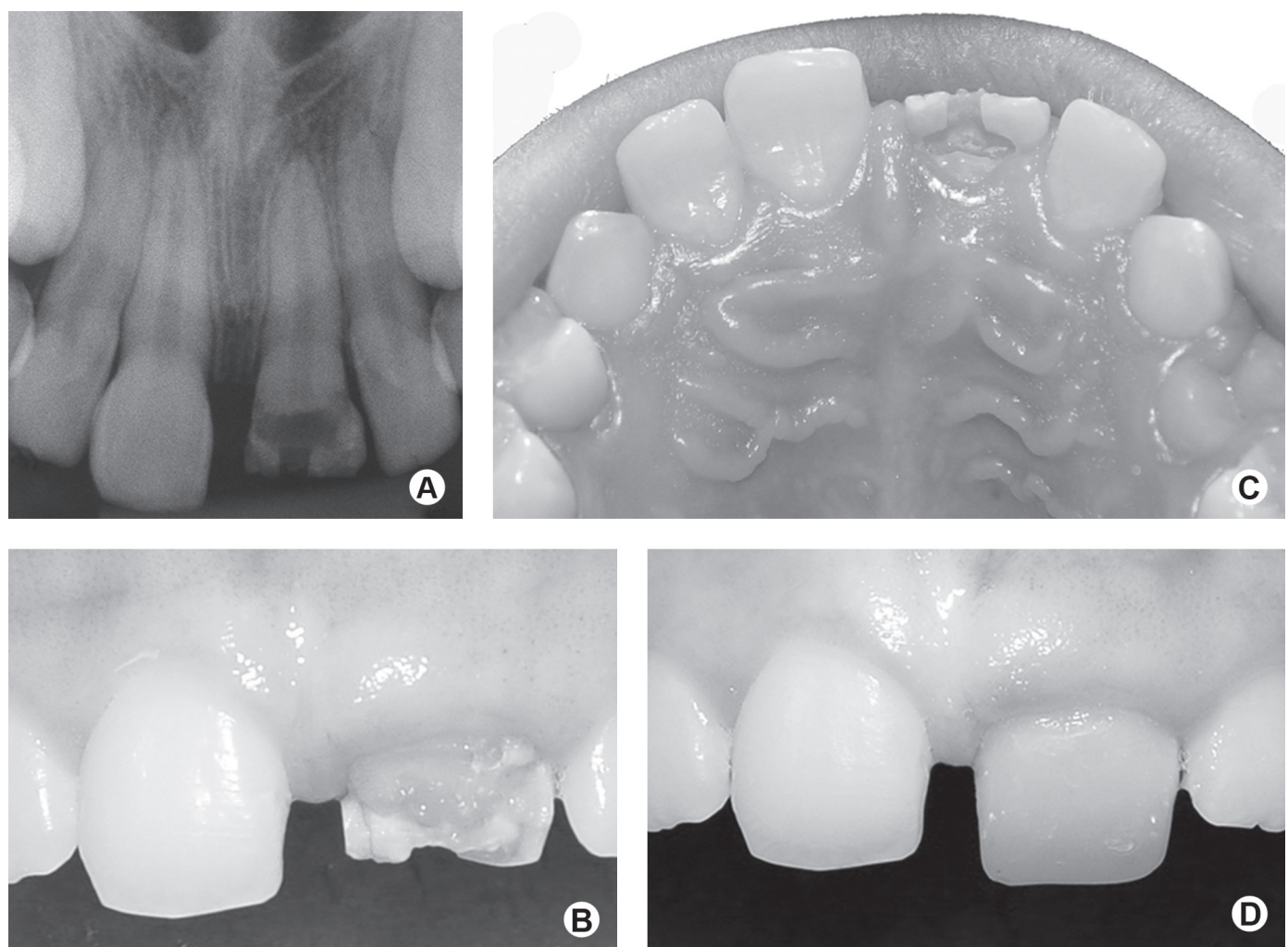

Figure 2. Case 2. A: Periapical radiograph of the permanent maxillary left central incisor, showing the presence of crown dilaceration. B: Clinical aspect of the buccal face of the permanent maxillary left central incisor. C: Incisal and palatal views of the tooth showing palatal displacement. D: Clinical aspect after composite resin restoration. 
pulp capping with calcium hydroxide cement (Dycal; Dentsply Indústria e Comércio Ltda., Petrópolis, RJ, Brazil) and glass ionomer cement (Vidrion R; SSWhite, Rio de Janeiro, RJ, Brazil), the tooth was restored in the same way as described for Case 1 (Fig. 2D).

\section{Case 3}

A 9-year-old Caucasian male child was brought to the same Pediatric Dentistry Clinic with esthetic complaints on the maxillary right central incisor. The child's health was good, with no history of systemic diseases. According to the mother's report, the patient had suffered trauma to the anterior maxilla at the age of 2 due to fall, causing intrusion of the primary maxillary right central incisor. The intruded primary tooth reerupted spontaneously and exfoliated at the normal time.

The radiographic (Fig. 3A) and clinical (Fig. 3B) examinations showed that the maxillary right central incisor presented crown dilaceration affecting the incisal and middle thirds. Carious lesions were observed on both buccal and palatal faces of the tooth crown along the junction between the dilacerated and non-dilacerated portions, probably due to the greater accumulation of biofilm in this region. There were hypoplastic areas on the incisal third of the dilacerated tooth crown (Fig. 3C), which was palatally displaced. Removal of the carious tissue, indirect pulp capping and composite resin restoration were done as described for Case 2 (Fig. 3D).

In all cases, the restorations were finished and polished in a subsequent session with fine- and extra-fine grain diamond burs (3195F and 3915FF; KG Sorensen, São Paulo, SP, Brazil) and aluminum oxide discs (SofLex; 3M ESPE). The parents/caregivers were instructed about the importance of attending the follow-up recall visits, maintaining rigorous oral hygiene at home, and avoiding foods and beverages that could stain the restorations.

\section{DISCUSSION}

Intrusive injuries in the primary dentition are
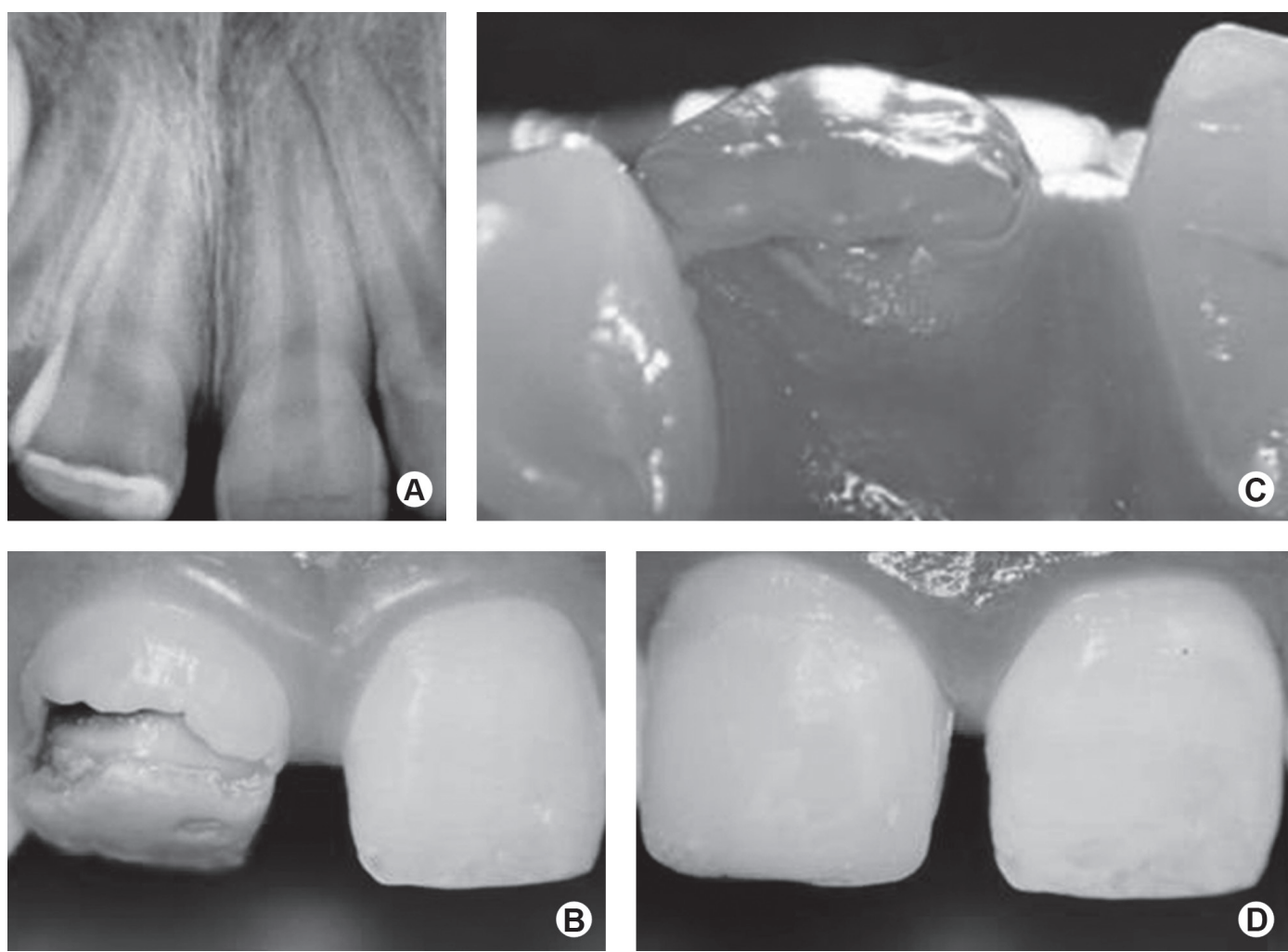

Figure 3. Case 3. A: Periapical radiograph of the permanent maxillary right central incisor showing crown dilaceration. B: Clinical aspect of the buccal face. C: Incisal and palatal views of the tooth showing palatal displacement of the crown. D: Clinical aspect after composite resin restoration. 
highly associated with developmental disturbances of their permanent successors. The reported prevalence of intrusive injuries affecting primary incisors varies from 4.4 to $22 \%$ and the percentage of developmental disturbances of the permanent incisors that could be attributed to injuries of their primary predecessors ranges from 12 to $74 \%$ (4). The children of the three cases presented in this paper suffered an intrusive luxation of the primary predecessor teeth around the age of 2 .

The disturbances to the permanent successor teeth due to trauma to the primary predecessors range from a simple white or yellow-brown discoloration to enamel hypoplasia, crown dilaceration, root duplication, root dilaceration, partial or complete arrest of root formation, odontoma-like malformation, sequestration of the permanent tooth germ, and disturbances of permanent successor eruption (4). The patients described in this paper presented crown dilaceration and white/ yellow-brown discoloration with enamel hypoplasia in the permanent anterior teeth as a result of trauma to the primary teeth.

Crown dilaceration can result from an intrusion of the primary incisor when a child is around the age of 2 years, when half the crown is already formed $(6,12-14)$. Subsequent to invasion of the partially formed follicle by the apex of the primary tooth, the permanent tooth crown twists lingually over the papilla $(15,16)$. The displaced enamel epithelium may become activated in the new position, forming a peculiar shape of deformed enamel projecting into the pulp canal or externally at the crown-root junction (11).

A radiological diagnosis of the sequelae to the permanent dentition can be established prior to tooth eruption (11), as observed in Case 2. The dilacerated crown appears foreshortened on the occlusal radiographic image in comparison to the adjacent crowns (16). Additionally, a lateral projection helps establishing a diagnosis and determining the direction of dilacerations (17). The radiographic examination is an important tool to identify pulpal complications, carious lesions and the severity of crown dilaceration, which will determine the treatment plan and case prognosis.

Teeth with dilacerated crowns may erupt normally or buccally or palatally/lingually displaced. Unfortunately, even without evidence of caries, they might later develop pulpal necrosis, followed by apical periodontitis and chronic abscess $(13,18)$. To avoid such complications, the dilacerated portion of the crown should be removed after its eruption, and a provisional crown should be placed until final restoration is made. In other cases, failure to erupt requires surgical exposure and orthodontic alignment followed by an esthetic restoration $(3,6,19-22)$. None of the children of this case series needed endodontic or orthodontic treatment.

The sequelae to the permanent dentition after trauma to the primary dentition might require only direct restorative procedures, but they frequently involve a multidisciplinary intervention also associating the areas of Pediatric Dentistry, Orthodontics, Periodontics, Surgery and Prosthodontics, depending on their extension and severity $(3,11)$. None of the 3 cases presented in this paper needed orthodontic repositioning because the dilacerated teeth erupted normally and could be aligned and leveled only with the esthetic restorative treatment.

The cases hereby presented are illustrative of the need of a rigorous clinical and radiographic follow-up of children that suffer trauma to the primary dentition at an early age, in order to detect and treat as soon as possible the sequelae to the permanent successor teeth. For cases of crown dilaceration in the permanent dentition, composite resin restorations produce excellent results to recover both esthetics and function.

\section{REFERENCES}

1. Holan G, Ram D, Fuks AB. The diagnostic value of lateral extraoral radiography for intruded maxillary primary incisors. Pediatr Dent 2002;24:38-42.

2. Flores MT. Traumatic injuries in the primary dentition. Dent Traumatol 2002;18:287-298.

3. Küchler EC, Tannure PN, Costa Mde C, Gleiser R. Management of an unerupted dilacerated maxillary central incisor after trauma to the primary predecessor. J Dent Child 2012;79:30-33.

4. Diab M, el Badrawy HE. Intrusion injuries of primary incisors. Part III: Effects on the permanent successors. Quintessence Int 2000;31:377-384.

5. Arenas M, Barbería E, Lucavechi T, Maroto M. Severe trauma in the primary dentition - diagnosis and treatment of sequelae in permanent dentition. Dent Traumatol 2006;22:226-230.

6. Tewari N, Pandey RK. Multiple abnormalities in permanent maxillary incisors following trauma to the primary dentition. J Indian Soc Pedod Prev Dent 2011;29:161-164.

7. Andreasen JO. Traumatic Injuries to the teeth. 2nd Edition. St Louis: CV Mosby Co;1972:273-320.

8. Maragakis GM. Crown dilaceration of permanent incisors following trauma to their primary predecessors. J Clin Pediatric Dent 1995;20:49-52.

9. Matsuoka T, Sobue S, Ooshima T. Crown dilaceration of a first premolar caused by extraction of its deciduous predecessor: a case report. Endod Dent Traumatol 2000;16:91-94.

10. Lowe PL. Dilaceration caused by direct penetrating injury. Br Dent J 1985;159:373-374.

11. Nelson-Filho P, Silva RA, Faria G, Freitas AC. Odontoma-like malformation in a permanent maxillary central incisor subsequent to trauma to the incisor predecessor. Dent Traumatol 2005;21:309- 
312.

12. Andreasen JO, Ravn JJ. The effect of traumatic injuries to primary teeth on their permanent successors. II. A clinical and radiographic follow-up of 213 injured teeth. Scand J Dent Res 1971;79:284294.

13. Kaufman AY, Keila S, Wasersprung D, Dayan D. Developmental anomaly of permanent teeth related to traumatic injury. Endod Dent Traumatol 1990;6:183-188.

14. Andreasen JO, Sundström B, Ravn JJ. The effect of traumatic injuries to primary teeth on their permanent successors. I. A clinical and histologic study of 117 injured permanent teeth. Scand J Dent Res 1971;79:219-283.

15. Von Arx T. Developmental disturbances of permanent teeth following trauma to primary dentition. Aust Dent J 1993;38:1-10.

16. Andreasen JO, Andreasen FM, Andersson L. Textbook and color atlas of traumatic injuries to the teeth. 4th ed. Oxford: Blackwell; 2007:770p

17. von Gool AV. Injury to the permanent tooth germ after trauma to the deciduous predecessor. Oral Surg Oral Med Oral Pathol 1973;35:2-12.

18. Prabhakar AR, Reddy VV, Bassappa N. Duplication and dilaceration of a crown with hypercementosis of the root following trauma: a case report. Quintessence Int 1998;29:655-657.

19. MacGregor SA. Management of injuries to deciduous incisors. J Can Dent Assoc 1969;35:26-34.

20. Wilson CF. Management of trauma to primary and developing teeth. Dent Clin North Am 1995;39:133-167.

21. van Gool AV. Lesions of the tooth germ following injury to the deciduous teeth. Rev Belge Med Dent 1986;41:96-99.

22. Wei YJ, Lin YC, Kaung SS, Yang SF, Lee SY, Lai YL. Esthetic periodontal surgery for impacted dilacerated maxillary central incisors. Am J Orthod Dentofacial Orthop 2012;142:546-551.

Received October 13, 2011

Accepted November 8, 2012 